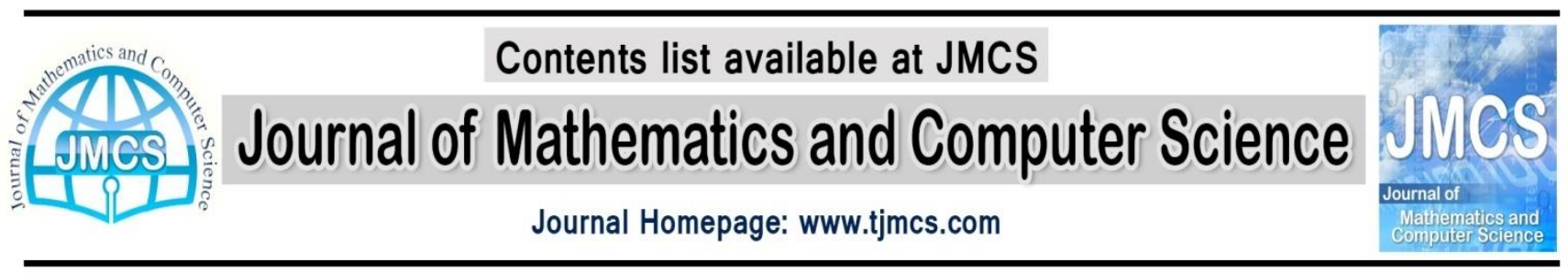

\title{
Simulation of Temperature Controller for an Injection Mould Machine using Fuzzy Logic
}

\author{
Seyed Kamaleddin Mousavi Mashhadi \\ Iran University of Science and Technology, school of Electrical Engineering, Tehran, Iran \\ Sk_Mousavi@iust.ac.ir \\ Mehdi Zahiri Savzevar \\ Khorasan Institute of Higher Education, Mashhad, Iran \\ Zahiry.mahdi@yahoo.com \\ Jamal Ghobadi Dizaj Yekan \\ Khorasan Institute of Higher Education, Mashhad, Iran \\ Jamal_Ghobadi@yahoo.com
}

Article history:

Received February 2013

Accepted March 2013

Available online April 2013

\begin{abstract}
This research introduces a method for designing a linear fuzzy controller to control the temperature in an injection mould machine. First, a time-delay system is introduced as the temperature control system. The fuzzy controller system is composed of a heater transfer function controller and a decision maker. Both the controller and the decision maker are designed using fuzzy logic, and simulated in MATLAB. For facilitating the implementation of the fuzzy circuit, a linear equation is estimated from fuzzy equations using regression method, and its response is compared to that of the fuzzy controller. Finally, a PID controller is designed and its response is compared to the response of the fuzzy system.
\end{abstract}

Keywords: Fuzzy-PID, Temperature Control, Fuzzy Controller, PID Controller.

\section{Introduction.}

Fuzzy logic plays such a special role in control issues that it is considered as an intelligent controlling method. In this paper the fuzzy method is used to control the temperature and as we see the response gets better in this method. Three articles are used as basic references to complete this paper. In [1], Prabha has modeled the heater of injection mould machine as a transfer function with time delay as follow:

$G(S)=\frac{\mathrm{Ke}^{-\tau \mathrm{s}}}{\mathrm{TS}+1}$

In this paper the same transfer function has been used to model the heater. In [2], Zhou has considered input/output membership functions of the fuzzy controller in terms of temperature and of triangle type. 
The same method has been used to design the fuzzy controller system described in section. in [3], hanamane, has implemented a controller using microprocessor to control the injection mould machine temperature. In aforementioned paper the implementation of this controller using fuzzifier and defuzzifier has been argued and a flowchart algorithm with a fuzzy controller has been proposed. In this paper we have used the same algorithm to simulate the fuzzy controller.

Implementing fuzzy rules in integrated circuits has some difficulties such as complex input/output rules and computing decimal numbers. In this paper a linear time invariant equation has been estimated from fuzzy rules using regression method. This equation facilitates modeling the fuzzy system and implementation of fuzzy rules in integrated circuits [4].

\section{System transfer function}

The system transfer function in general is as follow:

$\mathrm{G}(\mathrm{s})=\frac{\mathrm{Ke}^{-\tau \mathrm{s}}}{\mathrm{TS}+1}$

Where, $\mathrm{k}$ represents the gain, $\mathrm{T}$ system delay and $\mathrm{T}$ time constant.

Analyzing injection mould machine concludes that the transfer function possesses one degree of freedom and a time delay as follow:

$\mathrm{G}(\mathrm{s})=\frac{0.92}{144 \mathrm{~s}+1} \mathrm{e}^{-3 \mathrm{~s}}$

The open loop system is stable and tracks the set point after a time constant, which is about 560 seconds. To see the advantages of the fuzzy controller, the close loop system results of a pid compensator is compared with that of the fuzzy compensator. Then a fuzzy controller and a switch as a controller are designed and the results are compared to analyze now fuzzy logic act as a controller.

\section{3-Controller design}

For aforementioned system a fuzzy and a pid controller are designed in MATLAB and the step results are plotted for each system.

\section{3-1-PID compensator design}

The pid compensator is designed so that the setting time of close loop system is reduced. The closed loop system with pid compensator is shown in fig 1.

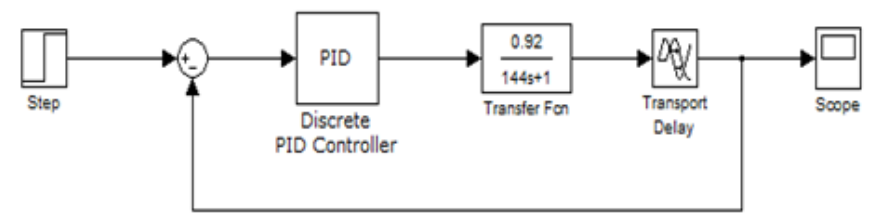

Figure1. closed loop system with pid compensator

System specifications with PID compensator are: 
PID compensator specifications are:

The closed loop system output whit PID compensator is shown in fig 2.

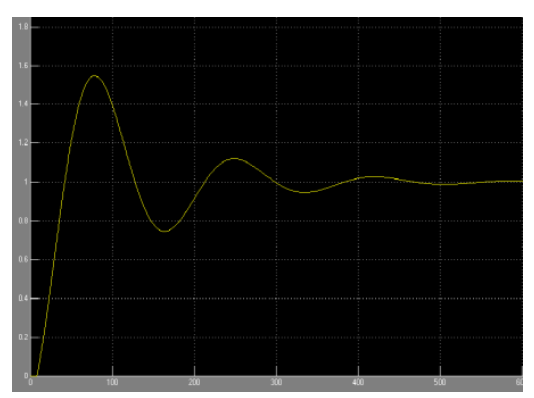

Figure2. closed loop system output whit PID compensator

According to fig 2 , the setting time is reduced to approximately 300 seconds and overshoots is $35 \%$ for this system.

\section{3-2-Fuzzy compensator design}

In a closed loop system with step inputs, the compensator outputs are 0 and the plant outputs are 1 ideally. Therefor, the input variable set point of compensator is assumed 0 and the output variable set point of compensator is assumed 1.

The membership functions are considered triangle type. Inputs/Outputs membership functions of fuzzy compensator are specified as follow:

Table1. Inputs/Outputs membership functions

\begin{tabular}{|c|c|}
\hline VN & Very negativ \\
\hline LN & Low negativ \\
\hline Z & zero \\
\hline LP & Low positiv \\
\hline VP & Very positiv \\
\hline
\end{tabular}

Inputs/Outputs membership functions are shown in fig 3 and fig 5, and their rules are shown in fig 4.

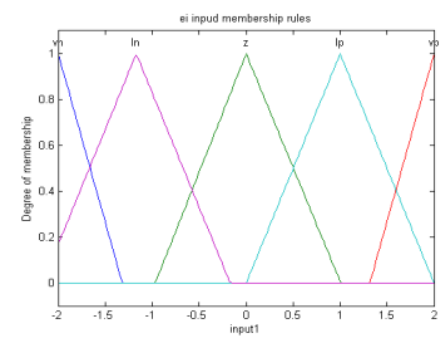

Figure3. Inputs membership functions 


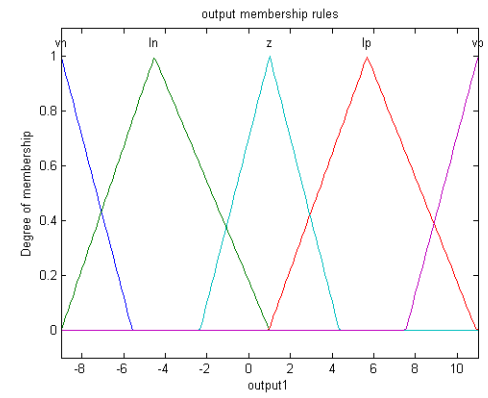

Figure4. Outputs membership functions

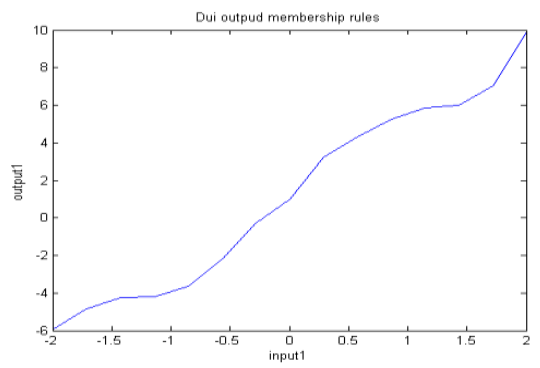

Figure5. surface controller in the state mamdani

The closed loop system with fuzzy compensator is simulated in MATLAB. The schema of simulation is shown in fig 6.

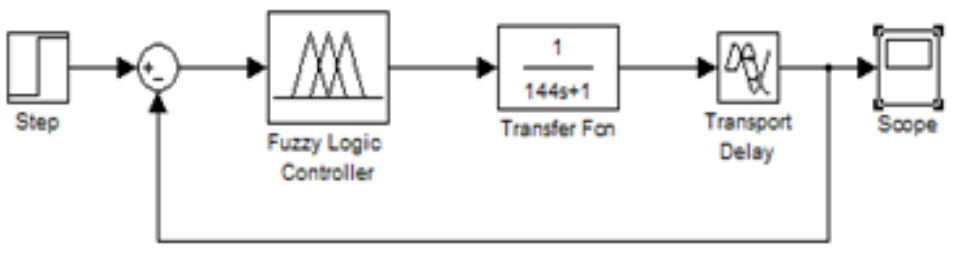

Figure6. schema of simulation

The step response of the close loop system with fuzzy compensator is shown in fig 7 


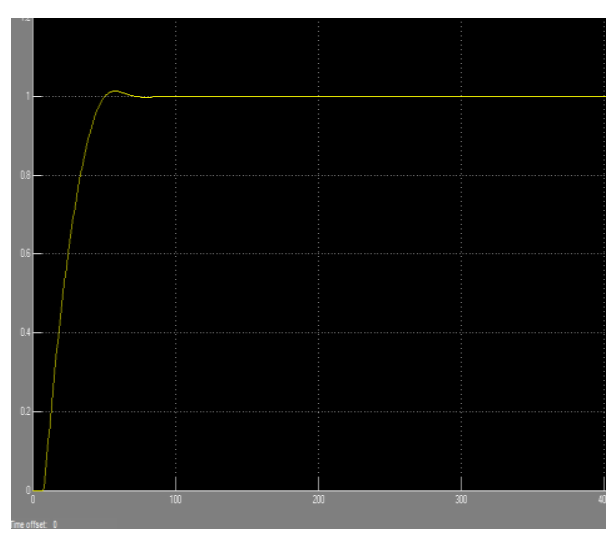

Figure7. step response of the close loop system with fuzzy compensator

Comparing the step results of close loop system with pid and fuzzy compensator we can see that the setting time is reduced from 300 seconds to 60 seconds and overshoot is reduced to 0.06 .

\section{4-temperature controller design}

Command circuit designed based on oven temperature which is red bye tristor (sensor). This output fed info command circuit. The temperature controller specifies the system input based on oven temperature to simulate this system. It is assumed that the desired oven temperature is 5 degree. To model the noise of the system we assume that the oven temperature variate alternatively between zero and 10 degrees. To simulate this noise a sinous wave with an average of 5 , amplitude of 5and a frequency of $0.1 \mathrm{rad} / \mathrm{s}$ is added to system outputs as shown in fig 8 . When the oven temperature is higher than 5 degrees, the temperature controller feeds a negative signal to the system to reduce the temperature and vice versa. The temperature controller is designed using a switch and fuzzy logic and the results are compared.

\section{4-1-Tempeature controller design using a switch}

Here an on-off switch is used as the temperature controller. So that when the oven temperature is higher than 5 degrees $(u>5)$, the switch applies a signal with a value of -4.9 to the system input and vice versa. It is expected that this negative value is compensate the oven temperature variations and a constant temperature of 5 degrees (the desired temperature) is achieved. The simulated temperature controller circuit with a switch is shown in fig 8.

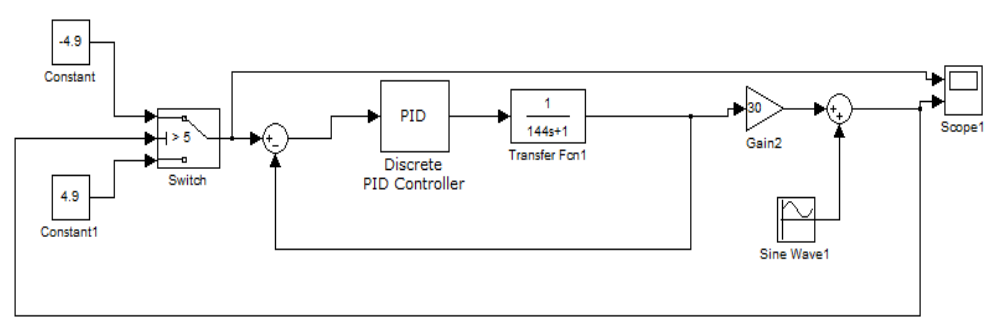

Figure8. simulated temperature controller circuit with a switch 
To relay the system output a voltage gain is used. The oven temperature variations using a pid compensator and a switch as the controller is plotted and show in fig 9.

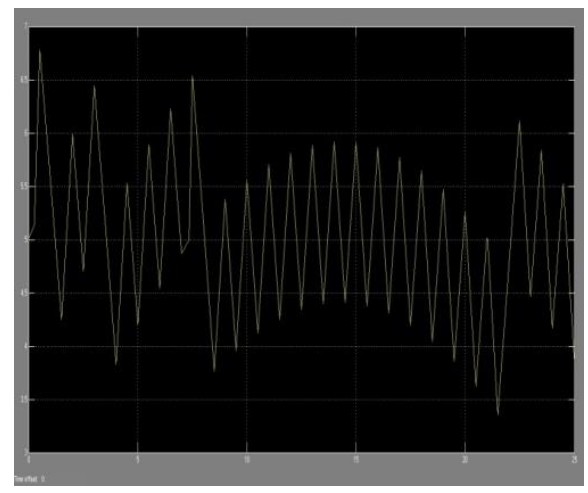

Figure9. pid compensator and a switch as the controller

The oven temperature variates between 3.3 and 6.8 degrees. It means that the tolerance is 1.8 degrees. But in critical situation, it needs to be almost constant or with a tolerance less than 0.5 degrees.

\section{4-2-Temperature controller design using fuzzy logic}

Here a temperature controller is design using the fuzzy logic. So that when the oven temperature rises, the fuzzy temperature controller applies a negative signal to reduce the temperature and vice versa. The value of the output signal of the controller computes according to fuzzy rules. Input and output variable membership functions are nominated as follow:

Table2.parameter of membership

\begin{tabular}{|r|c|}
\hline vvl & Very very low \\
\hline $\mathrm{vl}$ & Very low \\
\hline $\mathrm{l}$ & low \\
\hline $\mathrm{Il}$ & About low \\
\hline $\mathrm{lh}$ & About High \\
\hline $\mathrm{h}$ & High \\
\hline $\mathrm{vh}$ & Very High \\
\hline $\mathrm{vvh}$ & Very very High \\
\hline
\end{tabular}

The fuzzy rules bank is shown in table 3 . 
Table3. fuzzy rules bank

Then
\begin{tabular}{|c|c|}
\hline vhh & vll \\
\hline vh & vl \\
\hline $\mathrm{h}$ & $\mathrm{l}$ \\
\hline Ih & ll \\
\hline Il & lh \\
\hline l & h \\
\hline vl & vh \\
\hline vll & vvh \\
\hline
\end{tabular}

The degree of input and output member ship function and the relation of input-output rules are respectively shown in fig 10, 11, 12.

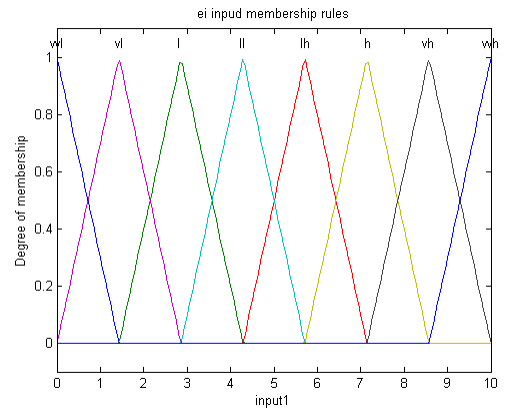

Figure10. Inputs membership functions

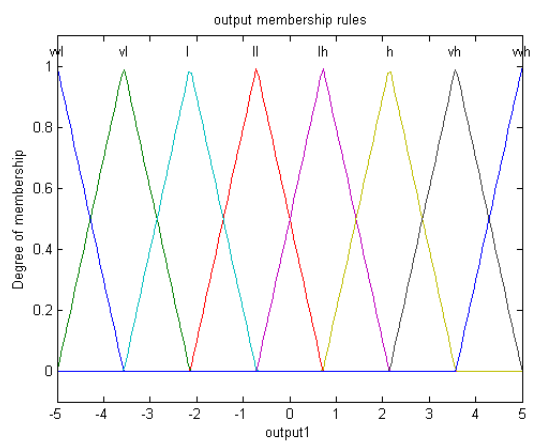

Figure11.output membership functions 


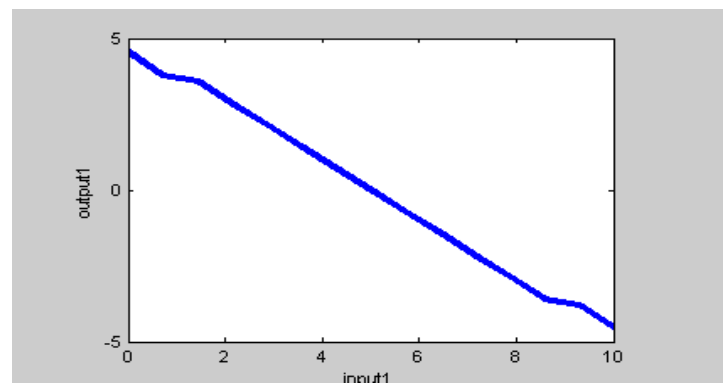

Figure12. surface controller in the state mamdani

The system with fuzzy controller is simulated in MATLAB and shown in fig 13.

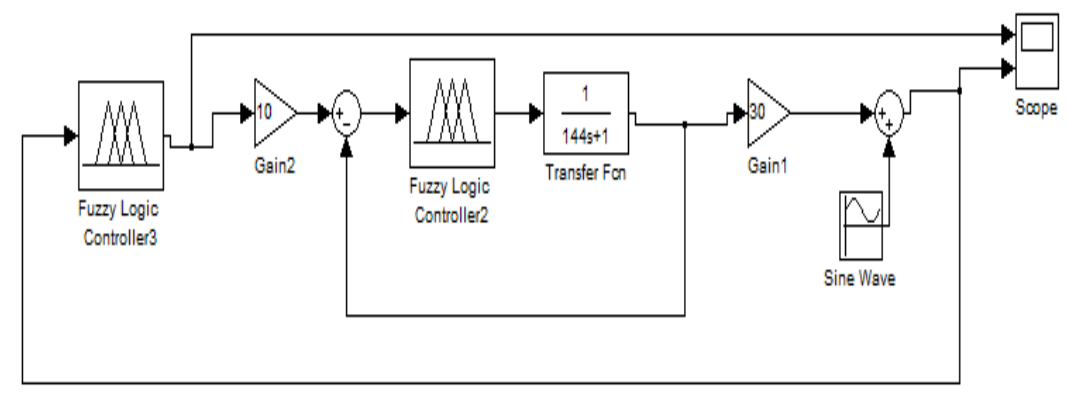

Figure13. with fuzzy controller is simulated in MATLAB

To modeling the noise of the system a sinous wave whit an average of 5 , amplitude of 5 and a frequency of $0.1 \mathrm{rad} / \mathrm{s}$ is added to system output as shown in fig 14.

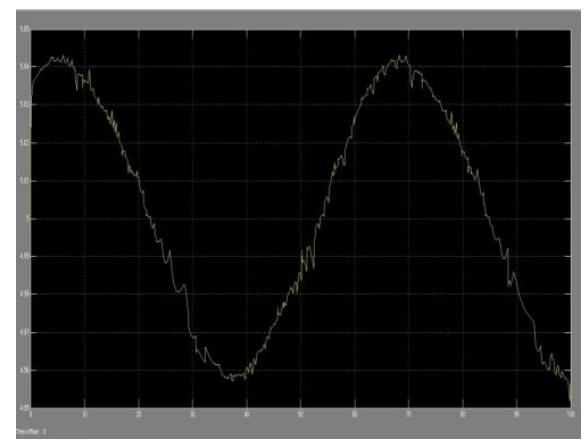

Figure14. amplitude of 5 and a frequency of $0.1 \mathrm{rad} / \mathrm{s}$ is added to system output

The oven temperature variates between 4.55 and 5.45 degrees. It means that the tolerance is 0.45 degree.

\section{5-Implimentation of fuzzy system using regression}

Here a linear equation is obtained from complicated fuzzy equation using regression method and compared with fuzzy methods response.

The linear equation is formulated as:

$\mathrm{y}=\mathrm{p}_{0} \mathrm{x}+\mathrm{p}_{1}$ 
MATLAB is used in order to obtain coefficients of regression equation. The regression equations are:

$\mathrm{p}_{0}=-0.9318$

$\mathrm{p}_{1}=4.6591$

In fig 15 , obtained equation is ploted. It is obvious that the regression, estimates the fuzzy rules, truly.

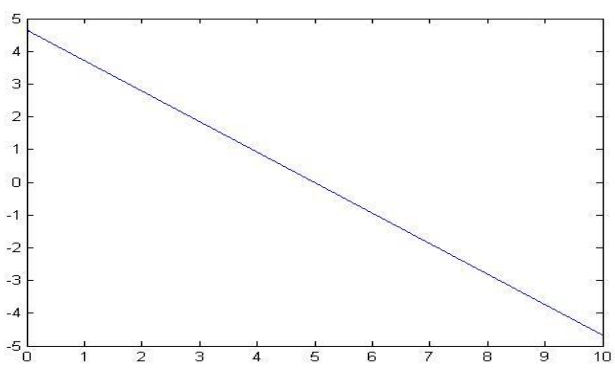

Figure15. obtained equation is ploted

To compare the results of fuzzy system and regression equation the system is simulated using a polynomial block as the temperature controller, shown in fig 16.

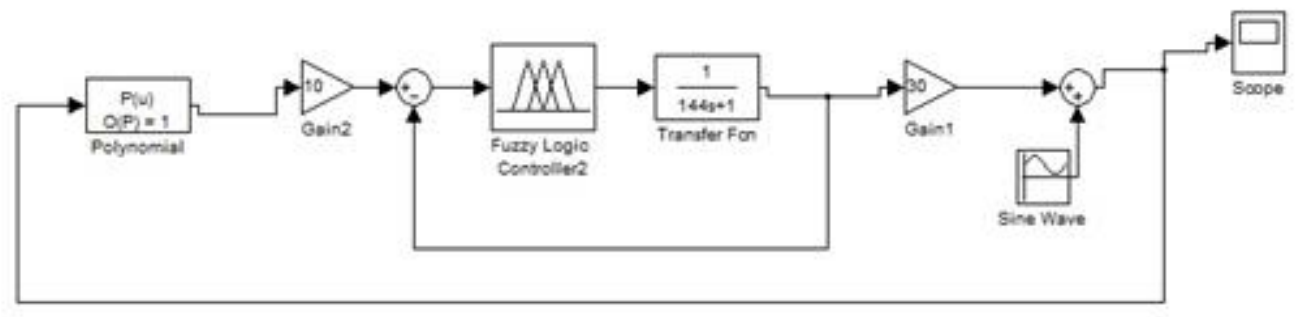

Figure 16. polynomial block as the temperature controller

The oven temperature as results of fuzzy controller and regression equation are shown in fig 17.

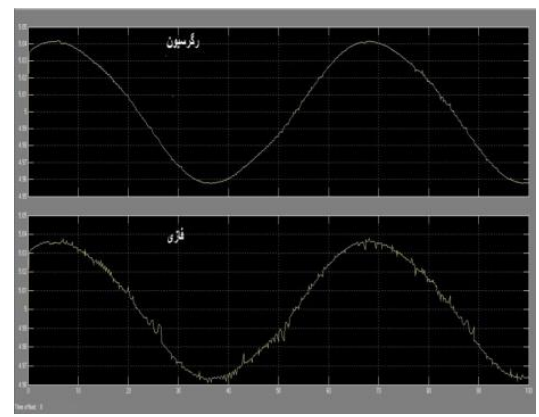

Figure17. as results of fuzzy controller and regression equation 
Comparing the output of fuzzy and it's regression we conclude that the regression of fuzzy system can be used instead of fuzzy rules with comfort implementation and almost well respons.

\section{References:}

[1] Dr. I Santi Prabha, K Durga Rao, D Siva Rama Krishna "Fuzzy Logic Based Intelligent Controller Design for an Injection Mould Machine Process Control” Department of ECE, EOW\&G Director of University, Vol No. 10, Issue No. 1, 098 - 103 (2011).

[2] H. Zhourll "Simulation on Temperature Fuzzy Control in Injection Mould Machine by Simulink" IMechanical School in South China U. of Technology, Guangzhou 510641(2008).

[3] M.D. Hanamane "Implementation of fuzzy temperature control using microprocessor" journal of scientific. Journal of scientific \& industrial researchVol.65, February, pp.142-147 (2006).

[4] Curve Fitting Toolbox ${ }^{\mathrm{TM}}$ User's GuideC COPYRIGHT 2001-2010 by The MathWorks, Inc.

[5] C.F. Juang, An automatic building approach to special Takagi-Sugeno fuzzy network for unknown plantmodeling and stable control, Asian J. Control 5 (2), pp. 176-186 (2003).

[6] C.F. Juang and C.T. Lin, "An on-line self-constructingneural fuzzy inference network and its applications", IEEE Trans. Fuzzy Systems 6, pp. 12-32 (1998).

[7] P.J. King, E.H. Mamdani, the Application of Fuzzy Control Systemto Industrial Processes. in IFAC world Congress.MIT.Boston (1975).

[8] K. Tanaka, M. Sugeno, "Stability analysis and design of fuzzy control systems" Fuzzy sets and systems, (1992). 